\title{
Proposal For Supply Chain Concentration In The Traditional MBA Program
}

\author{
K. V. Ramaswamy, Texas Southern University, USA
}

\begin{abstract}
The purpose of this proposal is to develop and implement a concentration in Supply Chain Management in the existing traditional MBA program effective fall 2012. Houston is the hub for many multinational oil and energy companies, large healthcare systems, wholesale/retail businesses, engineering and construction companies, and is a major city along the transportation artery of NAFTA. The program is designed to provide SCM expertise to students in the existing traditional MBA program. The environment for this proposal is the School of Business at Texas Southern University, Houston, Texas 77004.
\end{abstract}

Keywords: SCM; Supply Chain; Curriculum in SCM

\section{INTRODUCTION}

$\mathrm{n}$ their 2012 catalogue, the University of Houston Downtown mentions that more than $\$ 1,500$ billion of
materials are purchased by manufacturing firms and the expenditure for the purchase of materials and
services at federal, state and local government is of the order of $\$ 1,000$ billion. Chopra and Meindl (2004) define a supply chain as "consisting of all parties involved, directly or indirectly, in fulfilling a customer's request for a product or service". Van der Zee and Vander Vorst (2005) define supply chain management as "the integrated planning, coordination, and control of all logistic business processes and activities in the supply chain to deliver superior customer value at less cost to the supply chain as a whole while satisfying requirements of other stakeholders in the supply chain". Vakharia's (2002) perspective on supply chain management is "SCM is the art and science of creating and accentuating synergistic relationships among the trading partners in supply and distribution channels with the common shared objective of delivering products and services to the right customer, in the right quantity, and at the right time". According to Hausman (2001), SCM is one of the leading edge strategies for business process re-engineering, cost saving, and revenue enhancement today. The Institute of Supply Chain Management (2010), in a professionally conducted national survey, reports that the annual salary for the entry level SCM professional is $\$ 51,000$ and rises to about $\$ 268,000$ for senior levels, like Chief Purchasing/Supply Management professionals. Houston, where the author works, has considerable global involvement in the areas of energy, healthcare, manufacturing, wholesale and retail business, and requires professionals with knowledge and skills in the SCM area. This is the motivation for offering this concentration.

\section{PROGRAM DESCRIPTION}

\section{Program Goal}

The goal of the program is to provide traditional MBA students with a concentration in the field of Supply Chain Management (SCM). There is a growing need for graduates with skills in the SCM area because of the global scope of this activity in the fields of energy, healthcare, wholesale/retail operations, and transportation systems. SCM integrates, on a global scope, all the partners involved in manufacturing/service operations, purchasing, transportation, and distribution of products/services to maximize value to the customer while optimizing the performance of the supply chain. 


\section{Program Objectives}

1. To provide an understanding of a broad array of business concepts related to finance, accounting, economics, marketing, operations, statistics, and business law

2. To develop skills which enable the appropriate application of critical, analytical, and strategic thinking to the analysis of and development of solution to business problems

3. To improve the ability to utilize information technology and systems for effective decision-making, problem-solving, and communications

4. To work cooperatively with all the partners in the supply chain, develop strategies for improving the efficiency and effectiveness of the supply chain to maximize value to the customer

5. To develop a greater appreciation of workplace/supply chain diversity, ethical issues facing businesses today, and the challenges of the global sourcing issues and marketplace

The existing MBA core courses provide adequate exposure to items 1,2 and 3. The concentration provides exposure to items 4 and 5.

\section{Program Administration}

1. The Graduate Studies Committee, with input from graduate faculty of the Business School, will be responsible for curriculum development and review. The Chair of the Dept. of Business Administration will be responsible for curriculum delivery.

2. The Director of Graduate Programs of the Business School will be primarily responsible for recruiting, advising and supervision of the program. This person will also interface with the Graduate School for application review and admission recommendations.

3. The Graduate School, through its Dean, will have administrative control and will confer the MBA degree as per current university policy on graduate programs.

\section{SCM Concentration Requirements}

The concentration in SCM will consist of nine credit hours of course work in the current 36 credit hours MBA program which will be revised to accommodate the SCM concentration as follows.

SCM Concentration Courses

MGSC 625 - Introduction to Supply Chain Management

SCM 635 - Logistics System

3 Cr. Hrs. (Existing)

3 Cr. Hrs. (New)

Elective - Select one course from the following:

SCM 630 - Purchasing and Sourcing Strategy

SCM 640 - Simulation of Supply Chains

SCM 647 - Total Quality Management

3 Cr. Hrs. (New)

3 Cr. Hrs. (New)

3 Cr. Hrs. (New)

Required Core Courses in Existing Traditional MBA Program

BADM 630 - Managerial Communication

MGSC 671 - Information Technology

MGSC 624 - Statistical Analysis

ACCTG 631 - Seminar in Managerial Accounting

MGMT 636 - Organizational and Management Theory

FIN 621 - Financial \& Economic Analysis

FIN 652 - Managerial Finance

MKTG 650 - Strategic Marketing Management

MGMT 670 - Global Strategic Management
3 Cr. Hrs.

3 Cr. Hrs.

3 Cr. Hrs.

3 Cr. Hrs.

3 Cr. Hrs.

3 Cr. Hrs.

$3 \mathrm{Cr}$. Hrs.

3 Cr. Hrs.

3 Cr. Hrs. 
New Course Description

SCM 635 Logistics System

3 Cr. Hrs.

Concerned with the planning, implementation and control for the efficient and timely flow of materials, services and information in the supply chain.

Prerequisite: MGSC 625

SCM 630 Purchasing and Sourcing Strategy

3 Cr. Hrs.

Developing and Implementing procurement strategy, supplier relations management, global sourcing, contract negotiations and management.

Prerequisite MGSC 625

SCM 640 Simulation of Supply Chains

3 Cr. Hrs.

Using simulation software to understand and appreciate the impact of interrelated operations among the partners in the supply chain on the system output.

Prerequisite: MGSC 625

SCM 647 Total Quality Management

3 Cr. Hrs.

Implementation of continuous quality improvement using principles and tools of quality management and statistical process control.

Prerequisite: MGSC 625

\section{Program Evaluation}

During the first five years of the program, the Graduate Studies Committee of the School will assess the following on an annual basis:

Admission: Number of students admitted who are pursuing an SCM concentration, their overall undergraduate GPA, cumulative GPA in the graduate program, GPA in SCM concentration, years and type of employment experience, and demographics.

Program Outcomes: Data from the satisfaction survey of graduating students (SCM Concentration) and feedback from employers will be analyzed. Continuous improvement will be the basis of evaluation.

Placement of Graduates (SCM Concentration): The Director of Career Planning and Placement and the Graduate Program director will collect related data and analyze it. Continuous improvement will be the basis of evaluation.

Alumni Survey: The data from the survey will be used to evaluate the effectiveness of the program.

\section{Enrollment Projection for the First Five (5) Years of the Program:}

$\begin{array}{lc}\text { Academic Year } & \frac{\text { Projected Enrollment }}{\text { (MBA) }} \\ 2012-2013 & 10 \\ 2013-2014 & 12 \\ 2014-2015 & 15 \\ 2015-2016 & 20\end{array}$

\section{Additional Resources Required}

One full-time terminally qualified senior level faculty member with excellent academic research credentials in the

SCM area

Faculty development support

Additional software licensing fee

One graduate student assistant

Total
$\$ 120,000 /$ academic year

$\$ 10,000 /$ year

$\$ 5,000 /$ year

$\$ 10,000 /$ academic year

$\$ 145,000 /$ year 
We hope to have this concentration implemented in the not too distant future when the State's fiscal condition improves.

\section{AUTHOR INFORMATION}

Dr. K. V. Ramaswamy is a professor of Management Science in the Dept. of Business Administration at the Jesse H. Jones School of Business, Texas Southern University, Houston Texas. His Phd. is from Texas Tech University in the area of Operations Research. E-mail: ramaswamy_kv@tsu.edu

\section{REFERENCES}

1. Copra and Meindl (2004) “Supply Chain Management”, Second Edition, Pearson/Prentice Hall, Year 2004.

2. Hausman, Warren (2001), Founder of Supply Chain Online and Professor of Management Science and Engineering, Stanford University, website www.supplychainonline.com.

3. Institute of Supply Management Periodical, May 2010.

4. Vakharia, Asoo J.(2002) "e-Business and Supply Chain Management", Decision Sciences, Vol. 33, No.4.

5. Van Der Zee, D. J. and Van Der Vorst J. G. A. J. (2005) "A Modeling Framework for Supply Chain Simulation: Opportunities for Improved Decision Making” Decision Sciences, Vol.36, No. 1.

6. University of Houston Downtown Catalogue (2012), description of curriculum for a major in Supply Chain Management. 